\title{
Artesunate and Dihydroartemisinin Inhibit Rabies Virus Replication
}

\author{
Jun Luo ${ }^{1}$ Yue Zhang ${ }^{1} \cdot$ Yang Wang ${ }^{1} \cdot \mathrm{Qing} \mathrm{Liu}^{1} \cdot$ Jiesen $\mathrm{Li}^{1} \cdot$ Hongling $\mathrm{He}^{1} \cdot$ Yongwen Luo $^{1} \cdot$ \\ Shile Huang ${ }^{2,3}$ (i) $\cdot$ Xiaofeng Guo ${ }^{1}$
}

Received: 5 August 2020 / Accepted: 16 November 2020/Published online: 4 March 2021

(C) Wuhan Institute of Virology, CAS 2021

\begin{abstract}
Rabies is caused by infection of rabies virus (RABV) and remains a serious threat to the global public health. Except for the requirement for cold chain and high cost of human rabies immune globulin, no small molecule drugs are currently available for clinical treatment of rabies. So, it is of great importance to identify novel compounds that can effectively inhibit RABV infection. Artesunate (ART) and dihydroartemisinin (DHA), two derivatives of artemisinin, are widely used for treatment of malaria in adults and children, showing high safety. In this study, we found that both ART and DHA were able to inhibit RABV replication in host cells at a low concentration $(0.1 \mu \mathrm{mol} / \mathrm{L})$. The antiviral effects of ART and DHA were independent of viral strains and cell lines. Pre-treatment with ART or DHA for $2 \mathrm{~h}$ in vitro did not affect the viral replication in host cells, implying that ART and DHA neither reduced the viability of RABV directly nor inhibited the binding and entrance of the virus to host cells. Further studies revealed that ART and DHA inhibited RABV genomic RNA synthesis and viral gene transcription. Treatment with ART or DHA $(5 \mathrm{mg} / \mathrm{kg})$ by intramuscular injection improved, to some extent, the survival rate of RABV-challenged mice. Combination treatment with derivatives of artemisinin and mannitol significantly improved the survival rate of RABV-challenged mice. The results suggest that ART and DHA have a great potential to be explored as new anti-rabies agents for treatment of rabies.
\end{abstract}

Keywords Rabies virus (RABV) · Artemisinin · Dihydroartemisinin (DHA) · Artesunate (ART) · Antiviral

\section{Introduction}

Rabies is an acute zoonotic infectious disease caused by the rabies virus (RABV) that severely impacts the central nervous system. At present, there is no effective drug for treating rabies once clinical symptoms emerge. Rabies can be averted only by effective pre-exposure prophylaxis (PrEP) or post-exposure prophylaxis (PEP) (Franka et al.

Xiaofeng Guo

xfguo@scau.edu.cn

$\triangle$ Shile Huang

shuan1@1suhsc.edu

1 College of Veterinary Medicine, South China Agricultural University, Guangzhou 510642, China

2 Department of Biochemistry and Molecular Biology, Louisiana State University Health Sciences Center, 1501 Kings Highway, Shreveport, LA 71130-3932, USA

3 Feist-Weiller Cancer Center, Louisiana State University Health Sciences Center, Shreveport, LA 71130-3932, USA
2009). Most of rabies cases of human come from the bite or scratch by dogs (Fu 1997). Therefore, PrEP is mainly used in individuals who are in close contact with animals. Though rabies in animals can be prevented effectively by rabies vaccination, there are still more than 55,000 rabiesrelated human deaths annually worldwide (Hampson et al. 2015) because of no effective PEP treatment. PEP of rabies involves wound cleaning, rabies vaccination and rabies immune globulin injection. However, rabies immune globulin used for PEP needs cold-chain for transportation and is expensive, so many people in developing countries cannot afford it. In addition, PEP occasionally failed to prevent rabies-related deaths because of nonstandard and delayed treatment. Therefore, there is a great need for development of new cost-effective medications to treat rabies.

A number of antiviral agents against RABV have been reported (Du Pont et al. 2019). For instance, favipiravir can significantly inhibit RABV replication in vitro and improve the survival rate of RABV-infected mice after treatment (Yamada et al. 2016). TMR-001, a proprietary bulk drug 
substance solution of ranpirnase, can inhibit RABV release and cell-to-cell infection in vitro (Smith et al. 2020). Pyrimethamine inhibits RABV replication in vitro through the inhibition of adenosine synthesis (Rogee et al. 2019). Datura metel has a strong anti-RABV activity in vitro (Roy et al. 2016). $\lambda$-carrageenan P32 inhibits RABV replication through the inhibition of viral internalization and glycoprotein-mediated cell fusion (Luo et al. 2015). Nevertheless, none of them has been approved for clinical treatment of rabies.

Artemisinin and its derivatives (termed artemisinins), such as dihydroartemisinin (DHA) and artesunate (ART), are widely used for treatment of malaria in adults and children, showing high safety (Efferth 2017). Studies have demonstrated that artemisinins not only possess anticancer activity (Odaka et al. 2014; Wang et al. 2017), but also have antiviral effect (Capci et al. 2020; D'Alessandro et al. 2020). It has been described that ART inhibits the replication of human cytomegaloviruses in several cell lines (Efferth et al. 2002; Schnepf et al. 2011). In addition, ART displays a potent antiviral effect against hepatitis B virus (Romero et al. 2005) and human herpesvirus-6 (Milbradt et al. 2009). Furthermore, ART can also inhibit the replication of Epstein-Barr virus and human JC polyomavirus dose-dependently in cells (Auerochs et al. 2011). It has been shown that artemisinin and analogs exert their antihepatitis $\mathrm{C}$ virus activity by inducing reactive oxygen species (Obeid et al. 2013), while artemisinin inhibits the replication of flaviviruses by promoting the type I interferon production (Wang et al. 2020). Therefore, artemisinins act as promising antiviral agents through multiple mechanisms.

This study was set to determine whether ART and DHA can act as anti-RABV agents. Here we show that ART and DHA inhibited RABV infection in cells independently of RABV strains and cell lines. Mechanistically, ART and DHA inhibited RABV infection by impeding genomic RNA synthesis and transcription. Treatment with ART or DHA improved the survival rate of RABV-challenged mice. The results support that these anti-malarial drugs may be explored as potential anti-RABV agents.

\section{Material and Methods}

\section{Cells, Viruses, Compounds and Animals}

Mouse neuroblastoma (NA) cells (Wuhan Institute of Biological Products, Wuhan, China) were cultured in RPMI 1640 medium (Gibco, Suzhou, China) supplemented with $10 \%$ fetal bovine serum (FBS) (Gibco, Grand Island, New York, USA). Baby hamster kidney (BHK-21) cells (Wuhan Institute of Biological Products, Wuhan, China) were maintained in Dulbecco's-modified Eagle's medium (DMEM) (Gibco, Suzhou, China) containing 10\% FBS (Gibco). RABV challenge virus standard 11 (CVS-11) strain (a gift from Dr. Xianzhu Xia, Academy of Military Medical Sciences, Beijing, China) and rHEP-GFP strain (Luo et al. 2016b) were propagated in NA cells. Challenge virus standard 24 (CVS-24) stain (a gift from Dr. Zhenfang Fu, Huazhong Agricultural University, Wuhan, China) was propagated in the brains of suckling mice. GD-SH-01 is a wt RABV strain that was isolated from the brain tissue of rabid pig in our laboratory and is phylogenetically close to canine RABV (Luo et al. 2013). Both artesunate (ART) and dihydroartemisinin (DHA) were purchased from TCI America (Portland, OR, USA), and were dissolved in dimethyl sulfoxide (DMSO) for use. Female KM mice (6-7 weeks old) were provided by the Center for Laboratory Animal Science of the Southern Medical University (Guangzhou, China). Mice were housed in the Laboratory Animal Center of the South China Agricultural University.

\section{Cell Viability Assay}

The cytotoxicity of ART and DHA in NA and BHK-21 cells was evaluated using the methyl thiazolyl tetrazolium (MTT) assay as described previously (van Tonder et al. 2015). Briefly, cell monolayers cultured in 96-well plates were treated with $0-50 \mu \mathrm{mol} / \mathrm{L}$ of ART or DHA for $24 \mathrm{~h}$. Thereafter, MTT assay was performed and the absorbance at $562 \mathrm{~nm}$ with a $620 \mathrm{~nm}$ reference wavelength was recorded using a Ledetect96 Microplate Reader (Labexim Products, Lengau, Austria). The percentage of cell viability was calculated by comparing the absorbance values of compound-treated groups with those of DMSO-treated groups. The $50 \%$ cytotoxic concentration $\left(\mathrm{CC}_{50}\right)$ was calculated by nonlinear regression (curve fit) using Prism 6 (GraphPad Software, CA, USA). Each experiment was performed in triplicate.

\section{Virus Titration}

Virus titers were determined by dFA as described previously (Luo et al. 2016a). Briefly, NA cells grown in 96-well cell-culture plates were inoculated with tenfold serial dilutions of the indicated virus in RPMI 1640 medium and incubated for 2 days at $37{ }^{\circ} \mathrm{C}$ with $5 \% \mathrm{CO}_{2}$. Then, the used culture medium was discarded and cells were fixed with $80 \%$ acetone for $30 \mathrm{~min}$ at $-20{ }^{\circ} \mathrm{C}$. Cells were washed with phosphate-buffered saline (PBS) three times and then stained with FITC-labeled anti-RABV nucleoprotein $(\mathrm{N})$ antibodies (Fujirabio Inc., Malvern, PA, USA) at $37{ }^{\circ} \mathrm{C}$ for $60 \mathrm{~min}$. Subsequently, antigen-positive foci were counted under a fluorescence microscope (AMG, Washington, USA) and virus titers were calculated as focus 
forming units per milliliter (FFU/mL) using Karber method (Ramakrishnan 2016).

\section{Infection and Compound Treatment Experiments In NA and BHK-21 Cells}

NA or BHK-21 cell monolayers cultured in 6-well plates were infected with RABV rHEP-GFP or CVS-11 at a multiplicity of infection (MOI) of 3. After incubation for $1 \mathrm{~h}$ at $37^{\circ} \mathrm{C}$ with $5 \% \mathrm{CO}_{2}$, supernatants were removed and cells were washed with PBS three times. Next, fresh medium containing $10 \%$ FBS and $0.1 \mu \mathrm{mol} / \mathrm{L}$ of ART, DHA or equal volume of DMSO were added. Cells were then incubated at $37{ }^{\circ} \mathrm{C}$ with $5 \% \quad \mathrm{CO}_{2}$ for $24 \mathrm{~h}$ and supernatants were harvested. Then the cells were stained with FITC-labeled anti-RABV N antibodies and DAPI and fluorescent foci were analyzed under a fluorescence microscope (AMG, Washington, USA). Virus titers of samples were determined in NA cells by dFA, as described above. All titrations were carried out in triplicate.

\section{Assay for the Effects of ART and DHA on RABV's Viability and Entrance}

RABV rHEP-GFP and $0.1 \mu \mathrm{mol} / \mathrm{L}$ of ART, DHA or equal volume of DMSO were mixed completely and incubated at $37{ }^{\circ} \mathrm{C}$ for $2 \mathrm{~h}$. Then, NA cells cultured in 6-well plates were infected with the above pre-treated RABV at an MOI of 3 as described above. The supernatants were harvested after incubation for $24 \mathrm{~h}$. Virus titers in the cell culture supernatants were determined in NA cells by dFA. Green foci in cells infected with rHEP-GFP were analyzed under a fluorescence microscope.

\section{Quantitative Real-Time PCR}

NA cells cultured in 6-well plates were infected with RABV rHEP-GFP at an MOI of 3. After incubation for $1 \mathrm{~h}$ at $37{ }^{\circ} \mathrm{C}$, supernatants were removed and cells were washed with PBS three times. Then, fresh medium containing $10 \%$ FBS and $0.1 \mu \mathrm{mol} / \mathrm{L}$ of ART, DHA or equal volume of DMSO were added followed by incubation for $24 \mathrm{~h}$ at $37^{\circ} \mathrm{C}$. Next, cells were harvested and total RNA was extracted using TRIzol reagent (Invitrogen, Guangzhou, China) according to the manufacturer's protocol. Reverse transcription was performed using the Transcriptor First Strand cDNA Synthesis Kit (Vazyme Biotech Co., Ltd., Nanjing, China). Each reaction was performed in triplicate using SYBR Green Master Mix (Vazyme Biotech Co., Ltd.). Quantitative real-time PCR (qPCR) was performed in a CFX Connect Real-Time Detection System (Bio-Rad, Hercules, CA, USA). The levels of RABV genomic RNA (gRNA) and RABV nucleoprotein $(\mathrm{N})$ mRNA were normalized to glyceraldehyde-3-phosphate dehydrogenase (GAPDH). The primers used for qPCR were described previously (Luo et al. 2017).

\section{Animal Experiment}

KM mice (6-7 weeks of age) were inoculated through intramuscular (i.m.) route with $1.0 \times 10^{5} \mathrm{FFU}$ of CVS-11 or GD-SH-01 or 50 MILD $_{50}$ (mouse intracerebral lethal doses 50) of CVS-24. At 2 and 3 days post inoculation, mice were treated with ART, DHA or PBS by i.m. injection at a dose of $5 \mathrm{mg} / \mathrm{kg}$. The treatment dose referred previous studies (Tan et al. 2009; Held et al. 2015; Kume et al. 2016; Liu et al. 2017). Each group contained more than 10 mice. Survival rates were recorded daily for 3 weeks.

Mannitol treatment was performed as described previously (Dufkova et al. 2019; Martina et al. 2019). Briefly, KM mice (6-7 weeks of age) were inoculated through intramuscular (i.m.) route with $1.0 \times 10^{5} \mathrm{FFU}$ of CVS- 11 . At 2 and 3 days post inoculation, two groups of mice were treated with ART or DHA by i.m. injection at a dose of $5 \mathrm{mg} / \mathrm{kg}$. Two groups of mice were treated with PBS. Thirty minutes after the treatment with compounds, mice were treated intraperitoneally with $500 \mu \mathrm{L}$ of $25 \%$ mannitol in PBS in respective groups except one group treated with PBS. Each group contained 10 mice. Survival rates were recorded daily for 3 weeks.

\section{Statistical Analysis}

Data were presented as mean values \pm standard deviation (SD), and analyzed using Prism 6 (GraphPad Software, San Diego, CA, USA). The statistical significance was determined using Student's $t$ test or Logrank Mantel-Cox test. $P<0.05$ was considered to be significantly different.

\section{Results}

\section{ART and DHA Reduces the Cell Viability In A Concentration Dependent Manner}

Previous studies have shown that ART and DHA dosedependently inhibit the proliferation and induce apoptosis of human tumor cells (Odaka et al. 2014). Here, we tested whether ART and DHA are cytotoxic in mouse neuroblastoma NA and baby hamster kidney BHK-21 cells. As shown in Fig. 1, 24 h-treatment with ART or DHA decreased the viability of NA and BHK-21 cells in a concentration-dependent manner. The calculated $50 \%$ of cytotoxicity $\left(\mathrm{CC}_{50}\right)$ values for ART and DHA were approximately $64 \mu \mathrm{mol} / \mathrm{L}$ and $10 \mu \mathrm{mol} / \mathrm{L}$ in NA cells, respectively, and both more than $50 \mu \mathrm{mol} / \mathrm{L}$ in BHK-21 
Fig. 1 ART and DHA reduce the cell viability of NA (A) and BHK-21 (B) cells in a concentration-dependent manner. NA and BHK-21 cells cultured in 96-well plates were treated with DMSO, or $0-50 \mu \mathrm{mol} / \mathrm{L}$ of ART or DHA for $24 \mathrm{~h}$, followed by MTT assay. Absorbance at $562 \mathrm{~nm}$ with a $620 \mathrm{~nm}$ reference wavelength was recorded. The percentage of cell viability for each treatment was calculated by comparing the absorbance values of compound-treated cells with that of DMSO-treated cells. Each value is expressed as the mean \pm SD. $\mathrm{n}=8$. The $50 \%$ cytotoxic concentration $\left(\mathrm{CC}_{50}\right)$ was calculated by nonlinear regression (curve fit) using GraphPad Prism 6 software.
A

ART-NA

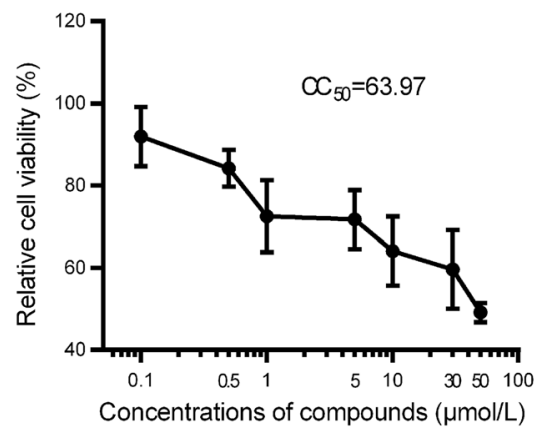

B

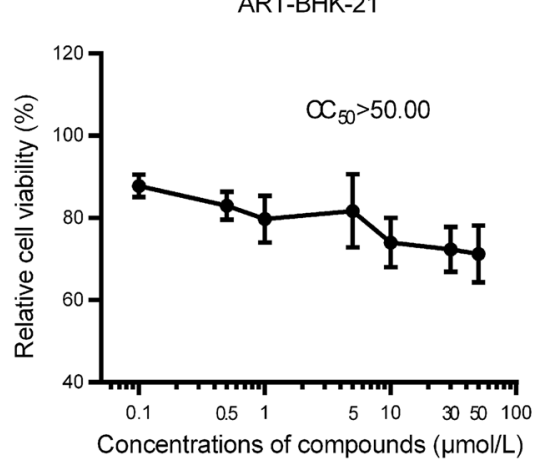

DHA-NA

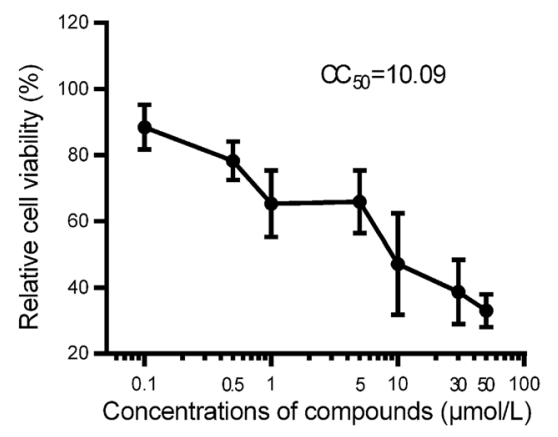

DHA-BHK-21

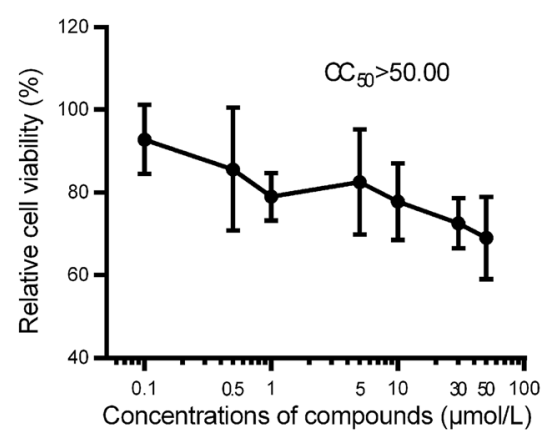

cells. At $0.1 \mu \mathrm{mol} / \mathrm{L}$, both ART and DHA showed limited cytotoxicity in NA and BHK-21 cells. Hence, this concentration was selected for our in vitro $\mathrm{RABV}$ replication experiments.

\section{ART and DHA Inhibit the Replication of RABV In Vitro}

To assess the in vitro anti-RABV activity of ART and DHA, NA and BHK-21 cells were infected with RABV rHEP-GFP or CVS-11 (MOI = 3) for $1 \mathrm{~h}$, followed by treatment with DMSO (vehicle control), or $0.1 \mu \mathrm{mol} / \mathrm{L}$ of ART or DHA for $24 \mathrm{~h}$. As shown in Fig. 2A, treatment with either ART or DHA was able to significantly inhibit the release of rHEP-GFP and CVS-11 strains in the culture media of NA cells and BHK-21 cells. As shown in Fig. 2B, treatment with either ART or DHA reduced the expression of RABV N protein in NA cells, indicating inhibition of RABV replication in the cells. Taken together, the results indicate that both ART and DHA were able to inhibit the replication of RABV in host cells.

\section{ART and DHA Neither Reduce the Viability of RABV Directly Nor Inhibit the Entrance of the Virus to Host Cells}

Successful replication of RABV in host cells depends on not only the viability of the virus itself, but also the binding and entering of the virus to host cells (Luo et al. 2015). To understand how ART and DHA inhibit the replication of RABV, first of all, we wondered whether ART and DHA reduce the viability of $\mathrm{RABV}$ directly and/or inhibit the binding and entrance of the virus to host cells. For this, RABV rHEP-GFP was mixed with ART or DHA (at a final concentration of $0.1 \mu \mathrm{mol} / \mathrm{L}$ ), or DMSO (vehicle control), followed by incubation at $37{ }^{\circ} \mathrm{C}$ for $2 \mathrm{~h}$. Next, NA cells were treated with the above pre-treated RABV rHEP-GFP $(\mathrm{MOI}=3)$ for $1 \mathrm{~h}$ at $37{ }^{\circ} \mathrm{C}$. Subsequently, the inoculum was removed, and the cells were washed with PBS three times and refed with fresh medium. After 24 h-incubation, the cell culture supernatants were collected, followed by titration of the virus and analysis of green foci formation. We found that pre-incubation of rHEP-GFP with $0.1 \mu \mathrm{mol} /$ $\mathrm{L}$ of ART or DHA for $2 \mathrm{~h}$ did not significantly alter the titer of the virus (Fig. 3A), or the expression of GFP in NA cells, compared to pre-incubation with DMSO (Fig. 3B). These results imply that ART and DHA inhibit the replication of RABV neither through directly reducing the viability of RABV nor by interfering with the entrance of the virus to cells.

\section{ART and DHA Inhibit the Synthesis of RABV Genomic RNA and mRNA In Host Cells}

RABV is an enveloped, negative-sense, and single-stranded RNA virus (Luo et al. 2016b). To understand how 
A
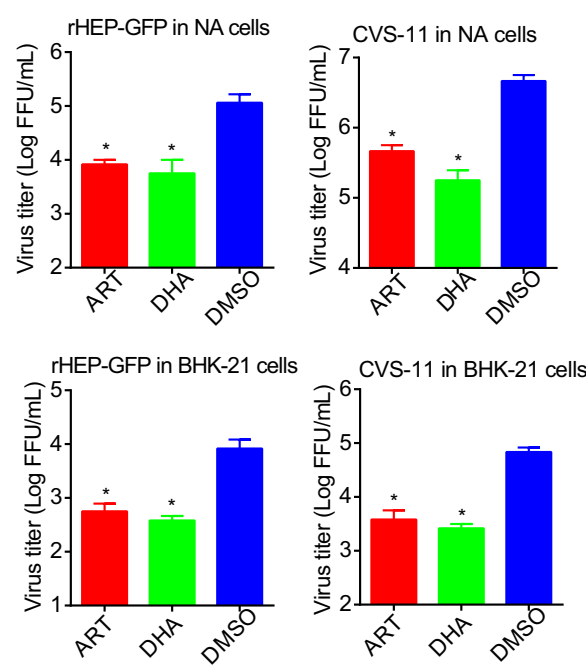

Fig. 2 ART and DHA inhibit the proliferation of RABV in cells. A ART and DHA inhibit the release of RABV from cells. NA or BHK-21 cells cultured in 6-well plates were infected with RABV rHEP-GFP or CVS-11 (MOI = 3) for $1 \mathrm{~h}$ at $37{ }^{\circ} \mathrm{C}$. Then, the infected cells were treated with DMSO (control), or $0.1 \mu \mathrm{mol} / \mathrm{L}$ of ART or DHA for $24 \mathrm{~h}$ at $37^{\circ} \mathrm{C}$. The cell culture supernatants were harvested to determine viral titers in NA cells by dFA, as described above. Titration value is expressed as the mean \pm SD. $n=3$. Asterisks
B

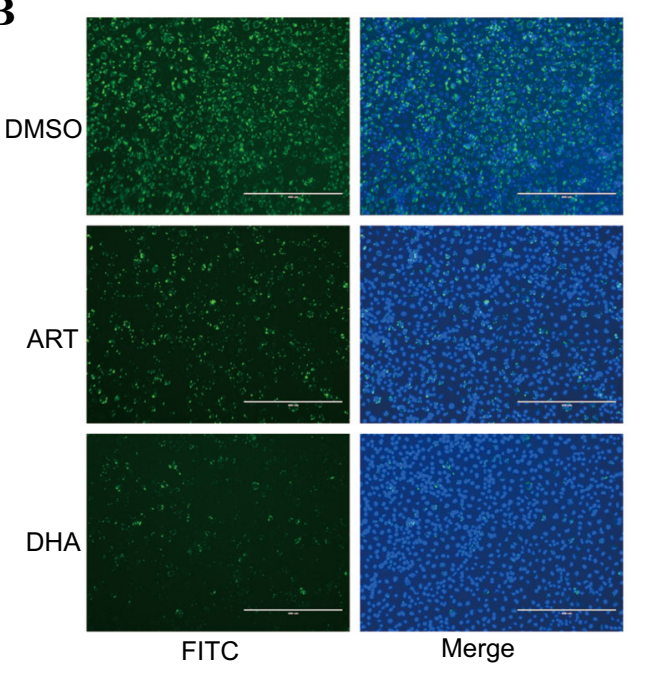

indicate significant differences, as calculated by Student's $t$ test $(* P<0.05)$. B ART and DHA inhibit the expression of RABV nucleoprotein $(\mathrm{N})$. NA cells were infected with RABV rHEP-GFP $(\mathrm{MOI}=3)$ for $1 \mathrm{~h}$ at $37^{\circ} \mathrm{C}$. Then, the infected cells were treated with DMSO (control), or $0.1 \mu \mathrm{mol} / \mathrm{L}$ of ART or DHA for $24 \mathrm{~h}$ at $37{ }^{\circ} \mathrm{C}$. Cells were stained with FITC-labeled anti-RABV $\mathrm{N}$ antibodies (green) and DAPI (blue) and fluorescent foci were analyzed under a fluorescence microscope (Scale bar: $400 \mu \mathrm{m}$ ).

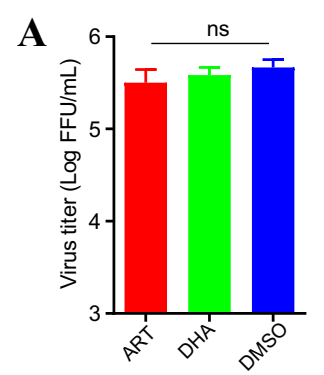

B

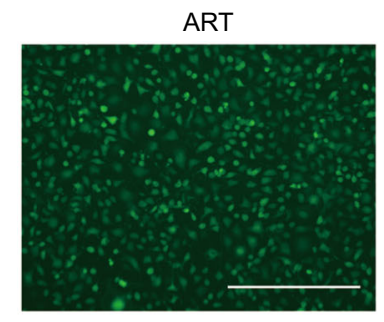

DHA

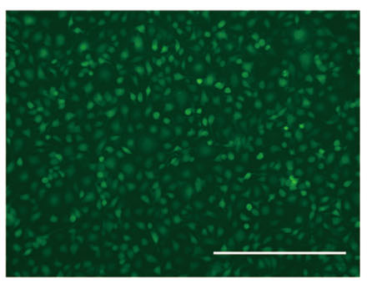

DMSO

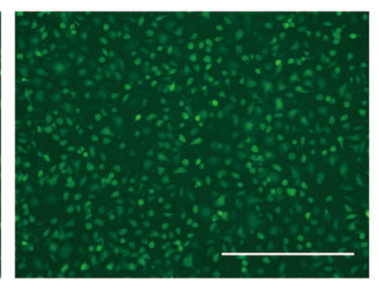

Fig. 3 ART and DHA neither reduce the titer of RABV directly nor interfere with the binding and entrance of RABV to host cells. RABV rHEP-GFP was completely mixed with DMSO (control), or $0.1 \mu \mathrm{mol} /$ $\mathrm{L}$ (final concentration) of ART or DHA, followed by incubation at $37{ }^{\circ} \mathrm{C}$ for $2 \mathrm{~h}$. Next, NA cells were treated with the above pre-treated RABV rHEP-GFP (MOI $=3$ ) for $1 \mathrm{~h}$ at $37^{\circ} \mathrm{C}$. Then, the inoculum was removed, and the cells were washed with PBS three times and re-

ART and DHA inhibit RABV replication, firstly we investigated whether the compounds suppress the synthesis of RABV genomic RNA (gRNA) in cells. To this end, NA cells were infected with RABV rHEP-GFP $(\mathrm{MOI}=3)$ for $1 \mathrm{~h}$ at $37{ }^{\circ} \mathrm{C}$, followed by $24 \mathrm{~h}$-treatment with ART, DHA or DMSO (vehicle control). Our qPCR analysis showed that treatment with ART or DHA significantly decreased the gRNA level of rHEP-GFP, compared to treatment with DMSO (Fig. 4A). The results indicate that ART and DHA inhibit the the synthesis of RABV genomic RNA.

Next, we studied whether ART and DHA inhibit the transcription of RABV in cells. Nucleoprotein $(\mathrm{N})$ is one of

fed with fresh medium containing $10 \%$ FBS. Following incubation for $24 \mathrm{~h}$, the cell culture supernatants were harvested. A Virus titers of the supernatants were determined in NA cells by dFA. Titration value is expressed as the mean $\pm \mathrm{SD}$. $\mathrm{n}=3$. "ns" indicates non-significant difference, as calculated by Student's $t$ test $(P>0.05)$. B Green foci in treated cells were analyzed under a fluorescence microscope (Scale bar: $400 \mu \mathrm{m})$.

the gene products of RABV (Luo et al. 2016b). By qPCR, we observed that treatment with ART or DHA significantly inhibited the expression of N mRNA in NA cells (Fig. 4B). Decreased transcription might inhibit virus production. Hence, we further determined the ratio of virus/genomicRNA. Of interest, treatment with ART or DHA did decrease the ratio of virus/genomic-RNA (Fig. 4C). The results demonstrated that ART and DHA inhibit RABV replication through repressing its genomic RNA synthesis and transcription. 


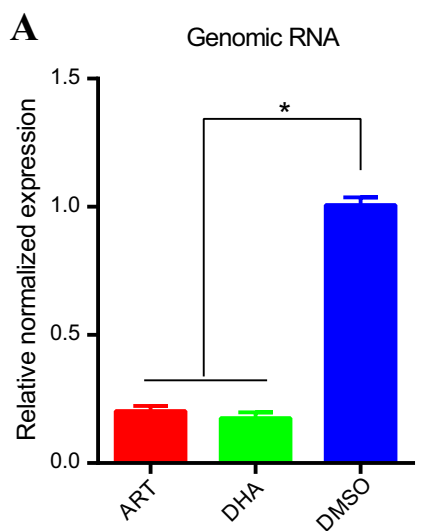

Fig. 4 ART and DHA inhibit the synthesis of RABV genomic RNA and mRNA in cells. NA cells were infected with RABV rHEP-GFP $(\mathrm{MOI}=3)$ for $1 \mathrm{~h}$ at $37^{\circ} \mathrm{C}$. Then, the infected cells were treated with DMSO (control), or $0.1 \mu \mathrm{mol} / \mathrm{L}$ of ART or DHA for $24 \mathrm{~h}$ at $37{ }^{\circ} \mathrm{C}$. qPCR was performed to determine the expression of RABV genomic

\section{Treatment with ART or DHA Improves the Survival Rate of Lethal RABV-Challenged Mice}

To test whether ART or DHA has a therapeutic potential for rabies, mice were challenged with pathogenic strains CVS-11,GD-SH-01 and CVS-24, and then treated with ART or DHA ( $5 \mathrm{mg} / \mathrm{kg}$ ), or PBS (control) by i.m. injection at 2 and 3 days post-infection. We chose the time points of compound treatment considering two points: one is to wait for RABV to invade into the CNS, and the second is to check the efficacy of treatment after $48 \mathrm{~h}$ of infection with RABV. As shown in Fig. 5, ART treatment modestly (by $25 \%$ ) but not significantly increased the survival rate of CVS-11, CVS-24 or GD-SH-01 challenged mice, compared to PBS treatment. DHA treatment also modestly increased the survival rate of mice infected with CVS-11, but not that of the animals infected with CVS-24 and GDSH-01. The results indicate that i.m. route treatment with ART or DHA has certain antiviral effect against RABV in vivo.

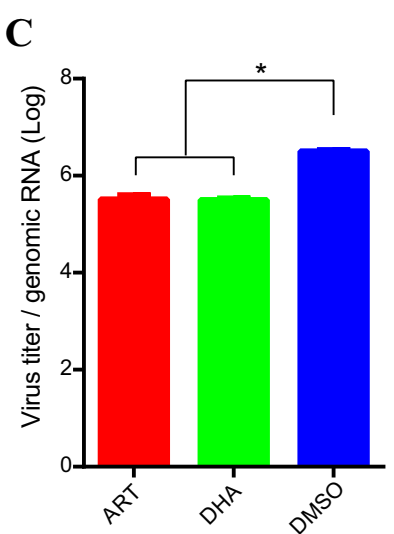

RNA (gRNA) and RABV N mRNA. The levels of gRNA (A) and N mRNA (B) were normalized to GAPDH. C Virus/genomic-RNA ratio was calculated based on the levels of gRNA and virus titer. The results represent the mean $\pm \mathrm{SD}$. $\mathrm{n}=3$. Asterisks indicate significant differences as calculated by Student's $t$ test $(* P<0.05)$.

\section{Combination Treatment with Derivatives of Artemisinin and Mannitol Significantly Improves the Survival Rate of Lethal RABV- Challenged Mice}

Intraperitoneal administration of $500 \mu \mathrm{L}$ of $25 \%$ mannitol was found to represent an effective dose for the enhancement of blood-brain barrier (BBB) permeability and has no visible effects in mice (Louboutin et al. 2010; Dufkova et al. 2019). To make compounds preferably passed through BBB, CVS-11 infected mice were treated with combination drugs (ART+ mannitol; DHA + mannitol). As shown in Fig. 6, mannitol treatment alone modestly but not significantly increased the survival rate of infected mice. Combination treatment with ART or DHA and mannitol significantly improved the survival rate of challenged mice (Fig. 6).
CVS-11

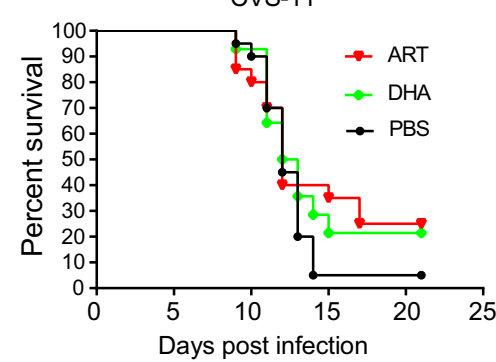

CVS-24

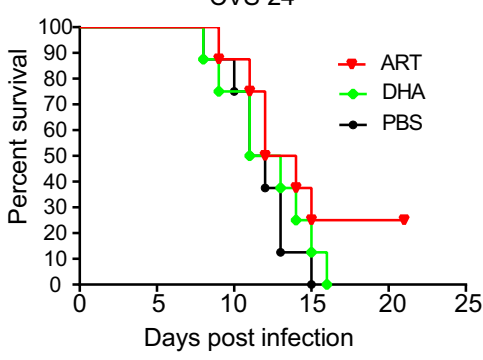

GD-SH-01

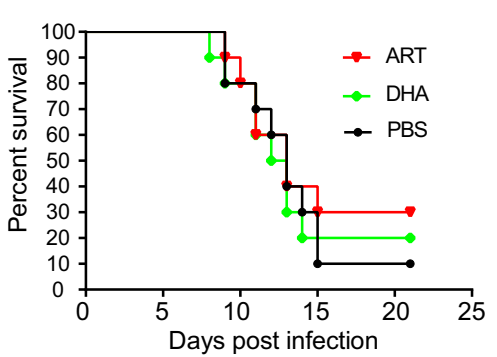

Fig. 5 ART and DHA improve the survival rate of lethal RABVchallenged mice. KM mice were infected with $1.0 \times 10^{5} \mathrm{FFU}$ of CVS-11, GD-SH-01 or 50 MILD $_{50}$ of CVS-24 through intramuscular (i.m.) route. At 2 and 3 days post infection, mice were treated with
PBS (control), or ART or DHA by i.m. injection at a dose of $5 \mathrm{mg} / \mathrm{kg}$. Survival rates were recorded daily for 3 weeks. The results represent the mean \pm SD. $\mathrm{n}=10$. Data are analyzed by Logrank Mantel-Cox test $(P>0.05)$. 


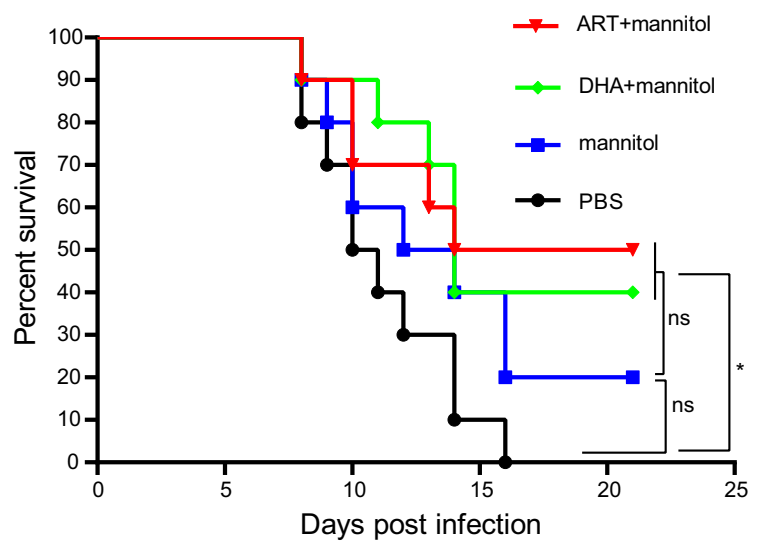

Fig. 6 Mannitol treatment enhances the inhibitory effect of ART and DHA on CVS-11. KM mice were infected with $1.0 \times 10^{5} \mathrm{FFU}$ of CVS-11 through i.m. route. At 2 and 3 days post infection, mice were treated with ART, DHA or PBS. Thirty minutes after the treatment with compounds, mice were treated intraperitoneally with $25 \%$ mannitol in respective groups. Survival rates were recorded daily for 3 weeks. The results represent the mean \pm SD. $n=10$. Data are analyzed by Logrank Mantel-Cox test $\left({ }^{*} P<0.05\right.$, ns: non-significant differences).

\section{Discussion}

In the present study, for the first time, we present evidence that anti-malarial drugs ART and DHA possessed antiviral activity against $\mathrm{RABV}$ in vitro (in cells) and in vivo (in mice). In this study, normal baby hamster kidney fibroblasts (BHK-21) were found to be highly resistant to DHA or ART $\left(\mathrm{CC}_{50}\right.$ $>50 \mu \mathrm{mol} / \mathrm{L}$ ), which is in line with the previous findings (Odaka et al. 2014), supporting the high safety profiles of artemisinins (Efferth 2017). Since ART or DHA at $0.1 \mu \mathrm{mol} / \mathrm{L}$ $(100 \mathrm{nmol} / \mathrm{L})$ had limited cytotoxicity in both NA and BHK21 cells, we selected this concentration for our in vitro studies, in order to minimize the cytotoxic effect on RABV replication in the two cell lines. Both ART and DHA at such a nanomolar concentration were able to inhibit the replication of rHEP-GFP and CVS-11 strains in NA and BHK-21 cells, indicating that ART or DHA can potently inhibit RABV replication independently of viral strains and cell lines.

Previous studies have described multiple mechanisms of action of anti-RABV agents, such as inhibition of RABV internalization (Luo et al. 2015), inhibition of adenosine synthesis (Rogee et al. 2019), and inhibition of RABV release (Smith et al. 2020). In addition, ribavirin, a broadspectrum guanosine nucleoside analog, inhibits the virus infection by inhibiting mRNA expression (Kihira et al. 2014; Musser et al. 2015; Aljabr et al. 2016), which may be due to inhibition of mRNA capping (Kentsis et al. 2004). In this study, we observed that pre-treatment with $0.1 \mu \mathrm{mol} / \mathrm{L}$ of ART or DHA for $2 \mathrm{~h}$ in vitro did not affect the viral replication in host cells, implying that ART and DHA neither reduced the viability of RABV directly nor inhibited the entrance of the virus to host cells. However, treatment with ART or DHA profoundly inhibited the genomic RNA synthesis and $\mathrm{N}$ mRNA transcription of RABV, leading to inhibition of RABV replication. ART-mediated inhibition of viral gene expression has been documented in human cytomegaloviruses, herpesviruses and Epstein-Barr virus (Efferth et al. 2002; Milbradt et al. 2009; Auerochs et al. 2011). Therefore, here we propose that ART and DHA may execute the antiviral action by blocking the viral gene expression of RABV, thereby inhibiting the synthesis of viral proteins and consequently preventing the onset of subsequent steps of the viral lytic replication cycle.

In this study, we noticed that ART and DHA were able to potently inhibit RABV infection in cell culture, but only modestly improved the survival rate of RABV-infected mice. Bloodbrain barrier (BBB) blocks the delivery of some antiviral drugs and molecules to the central nervous system, which increases the difficulties to treat clinical rabies (Smith et al. 2019). We speculate that the weak in vivo anti-RABV effect of ART and DHA might be due to the fact that only limited amount of the compounds was passing through BBB after i.m. injection. Furthermore, ART can ameliorate BBB breakdown in malaria infection in mice (Souza et al. 2012; Du et al. 2017), which is not beneficial to RABV clearance (Roy et al. 2007; Roy and Hooper 2007). As a BBB opener, mannitol helped ART or DHA to improve the survival rate of RABV-infected mice. Therefore, enhanced BBB permeability boosts the inhibitory effect of ART or DHA on RABV. Previous studies have shown that artemisinin can pass through BBB through intranasal administration (Marijon et al. 2014; Long et al. 2020). It is worthy to test whether intranasal administration of ART or DHA is an effective therapeutic route for rabies. In addition, besides BBB permeability, challenge doses of lethal RABV may also weaken the curative effect of antiviral drug (Banyard et al. 2019). Favipiravir shows different anti-RABV effects in separate studies, which may be related to different RABV strains, different challenge doses or different routes of administration used (Yamada et al. 2016; Banyard et al. 2019). In this study, mice were inoculated (i.m.) with $1.0 \times 10^{5} \mathrm{FFU}$ of CVS-11, GD-SH-01 or $50 \mathrm{MILD}_{50}$ of CVS-24. We treated the RABV challenged mice with ART or DHA at a dose of $5 \mathrm{mg} / \mathrm{kg}$ by i.m. injection at 2 and 3 days postinfection. Further studies are required to determine the challenge doses/strains of RABV and the administration doses/routes/time points of drugs to improve the therapy effect.

In this study, treatment with ART improved the survival rate of CVS-11, CVS-24 or GD-SH-01 challenged mice, whereas treatment with DHA only improved the survival rate of CVS-11 challenged mice. DHA is an active metabolite of all artemisinins, including ART (Efferth 2017). It is unclear why ART displayed better therapeutic effect than DHA. Recently we have observed that ART could enhance the immune response of inactivated rabies vaccines (Luo et al. 2019). In addition, artemisinin-induced antiviral effect 
against flaviviruses is associated with enhanced host type I interferon response (Wang et al. 2020). Our previous studies have demonstrated that clearance of infected RABV needs boosted immune response (Luo et al. 2020a, b). In addition, the molecular weight of ART is 384.43 and the molecular weight of DHA is 284.35. However, ART is hydrosoluble while DHA is liposoluble. Likely, the improvement of the survival rate of GD-SH-01 and CVS-24 challenged mice by ART may be partly attributed to its better absorption and enhanced immune response in mice.

Increasing evidence indicates that a combination therapy with two-to-three drugs can exhibit better anti-RABV effect than a single drug therapy (Marosi et al. 2019; Smreczak et al. 2019). In particular, combination of ART with ganciclovir, foscarnet or cidofovir can result in moderate synergism in human cytomegalovirus infections (Drouot et al. 2016). To reposition ART or DHA for treatment of rabies, it would be interesting to assess whether ART or DHA is synergistic or additive with other antiviral drugs.

In summary, here we have shown that artemisinin derivatives ART and DHA possess anti-RABV activity in vitro and in vivo. Both of them can inhibit RABV genomic RNA synthesis and viral gene transcription. This study provides the first evidence that these two antimalarial drugs have a great potential as anti-RABV agents.

Acknowledgements We thank Dr. Xianzhu Xia (Academy of Military Medical Sciences) for providing the CVS-11 virus. We thank Dr. Zhenfang Fu (Huazhong Agricultural University) for providing the CVS-24 virus. This work was supported by the National Key Research and Development Program of China (2016YFD0500400), National Natural Science Foundation of China (31772742) and Natural Science Foundation of Guangdong (2015A03031103).

Author Contributions XG, JL and SH conceived and designed the experiments. JL, YZ, YW, QL, JL and HH performed the experiments. $\mathrm{JL}, \mathrm{XG}$ and SH analyzed the data. JL and YL wrote the manuscript and prepared the figures. XG and SH checked and finalized the manuscript. All authors read and approved the final manuscript.

\section{Compliance with Ethical Standards}

Conflict of Interest The authors declare no conflict of interest.

Animal and Human Rights Statement All animal experiments were approved by the Ethics Committee for Animal Experiments of the South China Agricultural University (ethics committee approval number: 2019014), and conducted in compliance with the Regulations for the Administration of Affairs Concerning Experimental Animals approved by the State Council of People's Republic of China.

\section{References}

Aljabr W, Touzelet O, Pollakis G, Wu W, Munday DC, Hughes M, Hertz-Fowler C, Kenny J, Fearns R, Barr JN, Matthews DA, Hiscox JA (2016) Investigating the influence of ribavirin on human respiratory syncytial virus RNA synthesis by using a high-resolution transcriptome sequencing approach. J Virol 90:4876-4888

Auerochs S, Korn K, Marschall M (2011) A reporter system for Epstein-Barr virus (EBV) lytic replication: anti-EBV activity of the broad anti-herpesviral drug artesunate. J Virol Methods 173:334-339

Banyard AC, Mansfield KL, Wu G, Selden D, Thorne L, Birch C, Koraka P, Osterhaus A, Fooks AR (2019) Re-evaluating the effect of Favipiravir treatment on rabies virus infection. Vaccine 37:4686-4693

Capci A, Lorion MM, Mai C, Hahn F, Hodek J, Wangen C, Weber J, Marschall M, Ackermann L, Tsogoeva SB (2020) (Iso)Quinoline-Artemisinin hybrids prepared through click chemistry: highly potent agents against viruses. Chemistry 26:12019-12026

D'Alessandro S, Scaccabarozzi D, Signorini L, Perego F, Ilboudo DP, Ferrante P, Delbue S (2020) The use of antimalarial drugs against viral infection. Microorganisms 8:85

Drouot E, Piret J, Boivin G (2016) Artesunate demonstrates in vitro synergism with several antiviral agents against human cytomegalovirus. Antivir Ther 21:535-539

Du Pont V, Plemper RK, Schnell MJ (2019) Status of antiviral therapeutics against rabies virus and related emerging lyssaviruses. Curr Opin Virol 35:1-13

Du Y, Chen G, Zhang X, Yu C, Cao Y, Cui L (2017) Artesunate and erythropoietin synergistically improve the outcome of experimental cerebral malaria. Int Immunopharmacol 48:219-230

Dufkova L, Sirmarova J, Salat J, Honig V, Palus M, Ruzek D, Fooks AR, Mansfield KL, Tordo N, Jochmans D, Neyts J, Martina B, Koraka P, Osterhaus ADME (2019) Mannitol treatment is not effective in therapy of rabies virus infection in mice. Vaccine 37:4710-4714

Efferth T (2017) From ancient herb to modern drug: artemisia annua and artemisinin for cancer therapy. Semin Cancer Biol 46:65-83

Efferth T, Marschall M, Wang X, Huong SM, Hauber I, Olbrich A, Kronschnabl M, Stamminger T, Huang ES (2002) Antiviral activity of artesunate towards wild-type, recombinant, and ganciclovir-resistant human cytomegaloviruses. J Mol Med (Berl) 80:233-242

Franka R, Wu X, Jackson FR, Velasco-Villa A, Palmer DP, Henderson H, Hayat W, Green DB, Blanton JD, Greenberg L, Rupprecht CE (2009) Rabies virus pathogenesis in relationship to intervention with inactivated and attenuated rabies vaccines. Vaccine 27:7149-7155

Fu ZF (1997) Rabies and rabies research: past, present and future. Vaccine 15(Suppl):S20-S24

Hampson K, Coudeville L, Lembo T, Sambo M, Kieffer A, Attlan M, Barrat J, Blanton JD, Briggs DJ, Cleaveland S, Costa P, Freuling CM, Hiby E, Knopf L, Leanes F, Meslin F, Metlin A, Miranda ME, Mueller T, Nel LH, Recuenco S, Rupprecht CE, Schumacher C, Taylor L, Natal Vigilato MA, Zinsstag J, Dushoff J (2015) Estimating the global burden of endemic canine rabies. PLoS Negl Trop Dis 9:e0003709

Held J, Supan C, Salazar CLO, Tinto H, Bonkian LN, Nahum A, Moulero B, Sie A, Coulibaly B, Sirima SB, Siribie M, Otsyula N, Otieno L, Abdallah AM, Kimutai R, Bouyou-Akotet M, Kombila M, Koiwai K, Cantalloube C, Din-Bell C, Djeriou E, Waitumbi J, Mordmueller B, Ter-Minassian D, Lell B, Kremsner PG (2015) Ferroquine and artesunate in African adults and children with Plasmodium falciparum malaria: a phase 2, multicentre, randomised, double-blind, dose-ranging, non-inferiority study. Lancet Infect Dis 15:1409-1419

Kentsis A, Topisirovic I, Culjkovic B, Shao L, Borden KL (2004) Ribavirin suppresses eIF4E-mediated oncogenic transformation by physical mimicry of the 7-methyl guanosine mRNA cap. Proc Natl Acad Sci USA 101:18105-18110 
Kihira S, Uematsu J, Kawano M, Itoh A, Ookohchi A, Satoh S, Maeda Y, Sakai K, Yamamoto H, Tsurudome M, O'Brien M, Komada H (2014) Ribavirin inhibits human parainfluenza virus type 2 replication in vitro. Microbiol Immunol 58:628-635

Kume A, Dang TMA, Shichiri M, Ishida N, Suzuki H (2016) Probucol dramatically enhances dihydroartemisinin effect in murine malaria. Malar J 15:472

Liu J, Hong X, Lin D, Luo X, Zhu M, Mo H (2017) Artesunate influences Th17/Treg lymphocyte balance by modulating Treg apoptosis and Th17 proliferation in a murine model of rheumatoid arthritis. Exp Ther Med 13:2267-2273

Long Y, Yang Q, Xiang Y, Zhang Y, Wan J, Liu S, Li N, Peng W (2020) Nose to brain drug delivery - a promising strategy for active components from herbal medicine for treating cerebral ischemia reperfusion. Pharmacol Res 159:104795

Louboutin J, Chekmasova AA, Marusich E, Chowdhury JR, Strayer DS (2010) Efficient CNS gene delivery by intravenous injection. Nat Methods 7:905-909

Luo Y, Zhang Y, Liu X, Yang Y, Yang X, Zheng Z, Deng X, Wu X, Guo X (2013) Characterization of a wild rabies virus isolate of porcine origin in China. Infect Genet Evol 17:147-152

Luo Z, Tian D, Zhou M, Xiao W, Zhang Y, Li M, Sui B, Wang W, Guan $\mathrm{H}$, Chen H, Fu ZF, Zhao L (2015) lambda-carrageenan P32 is a potent inhibitor of rabies virus infection. PLoS ONE 10:e140586

Luo J, Shi H, Tan Y, Niu X, Long T, Zhao J, Tian Q, Wang Y, Chen H, Guo X (2016a) Two potential recombinant rabies vaccines expressing canine parvovirus virion protein 2 induce immunogenicity to canine parvovirus and rabies virus. Vaccine 34:4392-4398

Luo J, Zhao J, Tian Q, Mo W, Wang Y, Chen H, Guo X (2016b) A recombinant rabies virus carrying GFP between $\mathrm{N}$ and $\mathrm{P}$ affects viral transcription in vitro. Virus Genes 52:379-387

Luo J, Zhang B, Wu Y, Tian Q, Zhao J, Lyu Z, Zhang Q, Mei M, Luo Y, Guo X (2017) Expression of interleukin-6 by a recombinant rabies virus enhances its immunogenicity as a potential vaccine. Vaccine 35:938-944

Luo J, Zhang Y, He H, Liu Q, Huang S, Guo X (2019) Artesunate enhances the immune response of rabies vaccine as an adjuvant. Vaccine 37:7478-7481

Luo J, Zhang B, Lyu Z, Wu Y, Zhang Y, Guo X (2020a) Single amino acid change at position 255 in rabies virus glycoprotein decreases viral pathogenicity. Faseb J 34:9650-9663

Luo J, Zhang B, Wu Y, Guo X (2020b) Amino acid mutation in position 349 of glycoprotein affect the pathogenicity of rabies virus. Front Microbiol 11:481

Marijon A, Bonnot G, Fourier A, Bringer C, Lavoignat A, Gagnieu MC, Bienvenu AL, Picot S (2014) Efficacy of intranasal administration of artesunate in experimental cerebral malaria. Malar J 13:501

Marosi A, Dufkova L, Forro B, Felde O, Erdelyi K, Sirmarova J, Palus M, Honig V, Salat J, Tikos R, Gyuranecz M, Ruzek D, Martina B, Koraka P, Osterhaus A, Bakonyi T (2019) Combination therapy of rabies-infected mice with inhibitors of proinflammatory host response, antiviral compounds and human rabies immunoglobulin. Vaccine 37:4724-4735

Martina BEE, Smreczak M, Orlowska A, Marzec A, Trebas P, Roose JM, Zmudzinski J, Gerhauser I, Wohlsein P, Baumgaertner W, Osterhaus ADME, Koraka P (2019) Combination drug treatment prolongs survival of experimentally infected mice with silverhaired bat rabies virus. Vaccine 37:4736-4742

Milbradt J, Auerochs S, Korn K, Marschall M (2009) Sensitivity of human herpesvirus 6 and other human herpesviruses to the broadspectrum antiinfective drug artesunate. J Clin Virol 46:24-28

Musser JM, Heatley JJ, Koinis AV, Suchodolski PF, Guo J, Escandon P, Tizard IR (2015) Ribavirin inhibits parrot bornavirus 4 replication in cell culture. PLoS ONE 10:e134080
Obeid S, Alen J, Nguyen VH, Pham VC, Meuleman P, Pannecouque C, Le TN, Neyts J, Dehaen W, Paeshuyse J (2013) Artemisinin analogues as potent inhibitors of in vitro hepatitis $\mathrm{C}$ virus replication. PLOS ONE 8:e81783

Odaka Y, Xu B, Luo Y, Shen T, Shang C, Wu Y, Zhou H, Huang S (2014) Dihydroartemisinin inhibits the mammalian target of rapamycin-mediated signaling pathways in tumor cells. Carcinogenesis 35:192-200

Ramakrishnan MA (2016) Determination of 50\% endpoint titer using a simple formula. World J Virol 5:85-86

Rogee S, Larrous F, Jochmans D, Ben-Khalifa Y, Neyts J, Bourhy H (2019) Pyrimethamine inhibits rabies virus replication in vitro. Antivir Res 161:1-9

Romero MR, Efferth T, Serrano MA, Castano B, Macias RI, Briz O, Marin JJ (2005) Effect of artemisinin/artesunate as inhibitors of hepatitis B virus production in an "in vitro" replicative system. Antivir Res 68:75-83

Roy A, Hooper DC (2007) Lethal silver-haired bat rabies virus infection can be prevented by opening the blood-brain barrier. J Virol 81:7993-7998

Roy A, Phares TW, Koprowski H, Hooper DC (2007) Failure to open the blood-brain barrier and deliver immune effectors to central nervous system tissues leads to the lethal outcome of silverhaired bat rabies virus infection, 1110-1118

Roy S, Mukherjee S, Pawar S, Chowdhary A (2016) Evaluation of In vitro Antiviral Activity of Datura metel Linn. Against rabies virus. Pharmacogn Res 8:265-269

Schnepf N, Corvo J, Pors MJ, Mazeron MC (2011) Antiviral activity of ganciclovir and artesunate towards human cytomegalovirus in astrocytoma cells. Antivir Res 89:186-188

Smith SP, Wu G, Fooks AR, Ma J, Banyard AC (2019) Trying to treat the untreatable: experimental approaches to clear rabies virus infection from the CNS. J Gen Virol 100:1171-1186

Smith TG, Jackson FR, Morgan CN, Carson WC, Martin BE, Gallardo-Romero N, Ellison JA, Greenberg L, Hodge T, Squiquera L, Sulley J, Olson VA, Hutson CL (2020) Antiviral ranpirnase TMR-001 inhibits rabies virus release and cell-to-cell infection in vitro. Viruses 12:177

Smreczak M, Orlowska A, Marzec A, Trebas P, Kycko A, Reichert M, Koraka P, Osterhaus A, Zmudzinski JF (2019) The effect of combined drugs therapy on the course of clinical rabies infection in a murine model. Vaccine 37:4701-4709

Souza MC, Paixao FH, Ferraris FK, Ribeiro I, Henriques M (2012) Artesunate exerts a direct effect on endothelial cell activation and NF-kappaB translocation in a mechanism independent of plasmodium killing. Malar Res Treat 2012:679090

Tan B, Naik H, Jang I, Yu K, Kirsch LE, Shin C, Craft JC, Fleckenstein L (2009) Population pharmacokinetics of artesunate and dihydroartemisinin following single- and multiple-dosing of oral artesunate in healthy subjects. Malar J 8:304

van Tonder A, Joubert AM, Cromarty AD (2015) Limitations of the 3-(4,5-dimethylthiazol-2-yl)-2,5-diphenyl-2H-tetrazolium bromide (MTT) assay when compared to three commonly used cell enumeration assays. BMC Res Notes 8:47

Wang L, Liu L, Wang J, Chen Y (2017) Inhibitory effect of artesunate on growth and apoptosis of gastric cancer cells. Arch Med Res 48:623-630

Wang X, Zheng B, Ashraf U, Zhang H, Cao C, Li Q, Chen Z, Imran M, Chen H, Cao S, Ye J (2020) Artemisinin inhibits the replication of flaviviruses by promoting the type I interferon production. Antivir Res 179:104810

Yamada K, Noguchi K, Komeno T, Furuta Y, Nishizono A (2016) Efficacy of favipiravir (T-705) in rabies postexposure prophylaxis. J Infect Dis 213:1253-1261 